\title{
When a Nudge Is Not a Nudge: Why GCQ Visual Cues in Metro Manila's Main Train Systems Fail
}

\author{
Jefferson Arapoc \\ University of the Philippines Los Banos \\ David Savage ${ }^{\dagger}$ \\ University of Newcastle, Australia
}

This study evaluated the nudging measures being implemented in Metro Manila's major train systems to draw important behavioral implications in understanding why some nudges fail and how we can make them work. To ensure the effectiveness of visual cues placed in major train systems in Metro Manila, these nudges must be informative, inclusive, and consistent in conveying important information to the commuting public. The establishment of a Philippines nudging unit can also support the government to design, test, and evaluate such nudging measures. Lastly, nudging should not be considered as a stand-alone policy tool, but rather as a small part of a bigger policy implementation process.

Keywords: nudge, visual cues, GCQ, COVID-19

\section{INTRODUCTION}

Metro Manila was placed under a General Community Quarantine (GCQ) which started on June 1, 2020. GCQ allows majority of industry players - ranging from food to retail - to resume their respective business operations to revive the country's waning economy (Ibañez, Espedido, \& Ang, 2020). While some restrictions were already lifted, the government continues to implement strict quarantine protocols, including physical distancing, to prevent another surge of COVID-19 cases. Moreover, mass transportation systems - particularly trains and point-to-point buses - are still running under limited capacity. Evidently, these special circumstances are causing overcrowding in several public spaces, including train stations, which makes the implementation of physical distancing protocols even more challenging. With the anticipation of this looming problem, the government adopted the use of visual cues to encourage people in following physical distancing protocols. However, pictures circulating on social media platforms, particularly of people ignoring these visual cues, stirred public debates on the effectiveness of these nudging measures in the country. This issue raises very important questions on why some nudges fail and how we can make them work.

\section{THE POWER OF NUDGE}

A nudge is an intervention that acts like an indirect encouragement to alter human actions without forcing them to do so (Thaler \& Sunstein, 2009). This approach deviates from traditional methods of 
enforcement — such as giving rewards and punishment — since it is primarily focused on choice design to influence human's cognitive processes in choosing a desired outcome without any forms of coercion. The guiding principle of nudging can be summarized by the term coined by Thaler and Sunstein (2003), called Libertarian paternalism. It emphasizes that a nudge is not a mandate but an intervention that still preserves people's free choice. For example, in encouraging people to eat healthy, putting fruits in grocery racks at eye-level is a nudge, while banning junk food is not (Thaler \& Sunstein, 2009).

In light of the COVID-19 pandemic, a lot of countries are now subscribing to nudge theory in encouraging desirable behavioral changes, such as frequent handwashing and physical distancing (UNDP, 2020). The most prevalent method to nudge people is through the use of visual cues. In fact, a number of nudging experiments have already established their effectiveness. For example, visible signages — such as handwashing reminders, or even arrow-shaped stickers pointing from toilets to the sink-are found to increase people's tendency to wash their hands after a toilet use (Botta, Dunker, Fenson-Hood, Maltarich, \& McDonald, 2008; Judah et al., 2009). In physical distancing, visual cues correct the public's tendency to measure distance based on their perception of personal space, or the range that is within a person's arm reach or sphere of control as defined by Cutting and Vishton (1995).

\section{FIGURE 1 \\ VISUAL CUES FOR PHYSICAL DISTANCING IN BAGUIO AND PASIG CITY ${ }^{1}$}

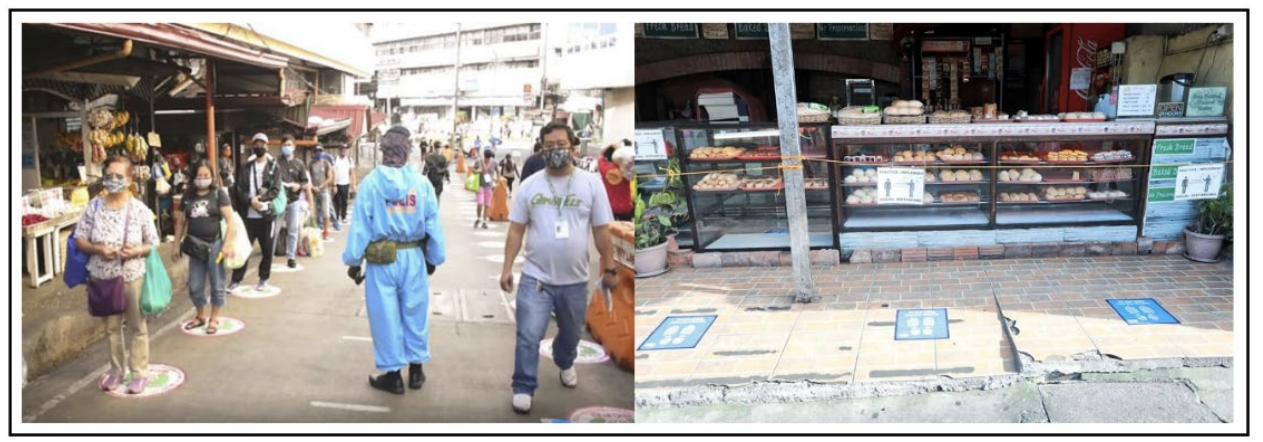

\section{NUDGING MEASURES IN METRO MANILA DURING GCQ}

In the Philippines, the use of visual cues was initially adopted by several Local Government Units (Figure 1). In Baguio City and Pasig City, pathways to public markets and business establishments were painted with bright visual icons, with footprint symbols, to maintain physical distancing (Madarang, 2020; Kabagani, 2020). These initiatives earned praises online due to their simplicity and effectiveness. It also inspired other government units in Metro Manila to replicate the measure in preparation for the implementation of the General Community Quarantine. Main train systems in the Metro-which include Light Rail Transit Line 1 (LRT 1), Light Rail Transit Line 2 (LRT 2), and Metro Rail Transit (MRT) —also adopted the measure to ensure the safety of the riding public. 


\section{FIGURE 2}

ONLINE VIRAL PICTURES OF PEOPLE NEGLECTING VISUAL CUES ${ }^{2}$

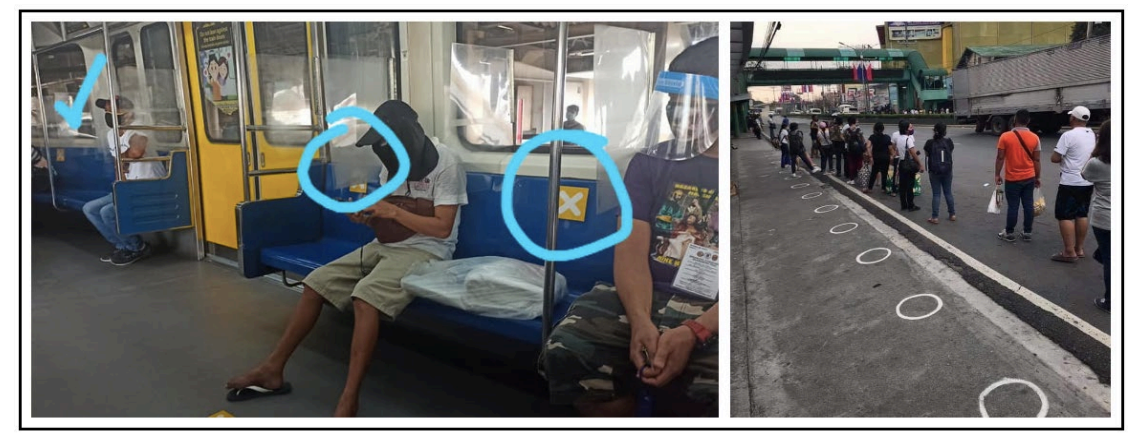

Interestingly, the implementation of some nudging measures seems to offer different results. Several pictures of people neglecting these visual cues trended online (Figure 2) which eventually led to a heated debate on whether or not Filipinos were just typically stubborn, or in Filipino slang, 'pasaway'. While human nature and socio-cultural factors might explain this puzzling outcome, there is no denying that the failure of a nudge can also stem from its poor design. An evaluation of nudging measures in Metro Manila's major train systems is a good starting point for us to draw important behavioral considerations to understand what went wrong, and how we can correct them.

\section{LACK OF CLEAR INFORMATION AND INCLUSIVENESS}

In Figure 3, it is evident that the three train lines have different approaches in promoting physical distancing. The management of LRT Line 1 and 2 decided to go with a soft-intervention approach, while MRT management decided to employ a more traditional one. The main difference between the two is that the former is more definitive on its target outcome, while the latter is merely suggestive and retains a person's free choice (Baldwin, 2014). Clearly, MRT's approach cannot be considered as a nudge. It is because MRT riders are forced to follow physical distancing protocols by making adjacent seats unavailable to them.

FIGURE 3

VISUAL CUES IN DIFFERENT MAJOR TRAIN SYSTEMS IN METRO MANILA ${ }^{3}$

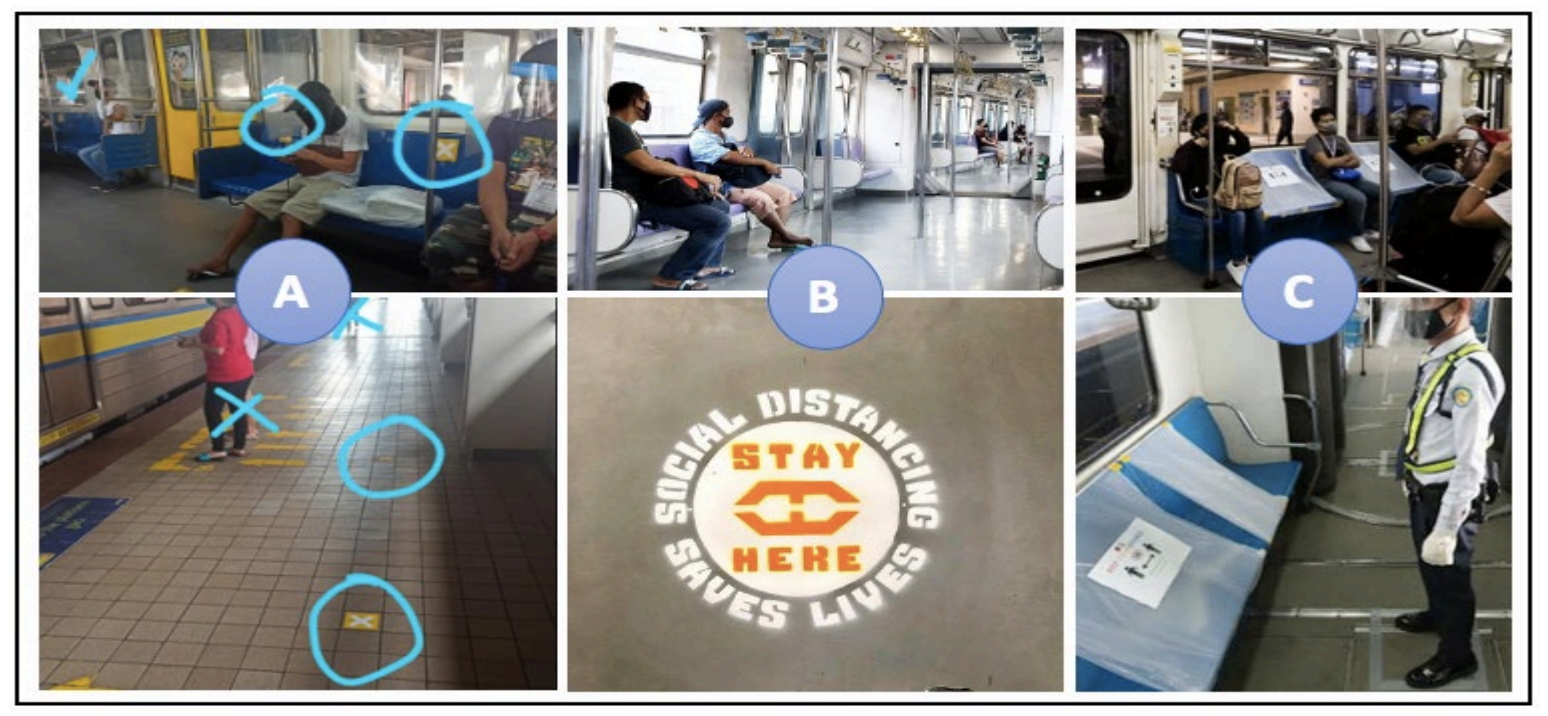


Nudging aims to lead people towards a particular outcome through subtle and indirect influences. While visual cues placed in LRT Line 1 and 2 appear to act like a nudge, their design fails to provide clear and relevant information. For example, LRT Line 1 decided to use ' $\mathbf{x}$ ' symbol to mark spaces where people should stand or sit. The problem with this symbol choice is that some people might associate the ' $\mathbf{x}$ ' symbol with things that are dangerous, forbidden, or wrong. It is important to note that humans have a tendency to be fallible in making sudden decisions. According to Kahneman (2011), a human mind is prone to systematic errors because of our tendency to look for shortcuts - such as the use of 'rule of thumbs' or heuristics. If a typical public commuter is in a rush to work, it is impossible for this person to listen or take notice of specific instructions on where to sit or stand, that is why visual cues have to convey clear information. Furthermore, a good nudge has to be inclusive. Information coming from visual cues must be understood across all ages and groups. Figure 4 shows a good example of an inclusive visual cue.

\section{FIGURE 4 \\ EXAMPLE OF AN INCLUSIVE VISUAL QUE IN NEW SOUTH WALES, AUSTRALIA}

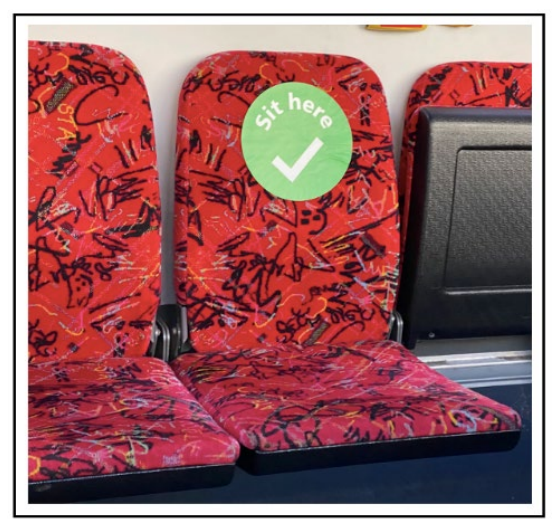

Aside from the visible text ${ }^{4}$ that explicitly states that you can 'sit here', two additional elements seem to further reinforce the visual cue's message - the color and the symbol. Color green is universally understood to mean 'go' (e.g., Traffic lights) and the 'check' symbol is often used to validate a correct action. Several studies support the idea that a human mind has a tendency to associate meaning to colors and symbols (Elliot \& Maier, 2014; Yoon \& Vargas, 2018). Figure 5 shows a proposed symbol color and symbol heuristics for visual cues. Visual cues that are designed to complement human cognitive biases are more inclusive because they can also cater to special types of public commuters - such as people with disabilities (PWD), illiterate, and kids.

FIGURE 5

PROPOSED SYMBOL COLOR AND SYMBOL HEURISTICS FOR VISUAL CUES ${ }^{5}$

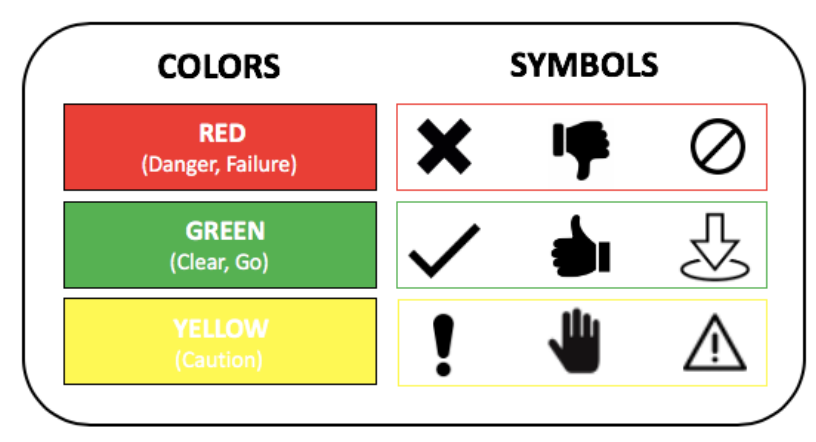




\section{INCONSISTENCY AND POOR DESIGN}

Given the independence of their respective operations, there is an apparent lack of consistency on the design of visual cues across train lines (recall Figure 3). While each management might have its own take on how to encourage physical distancing, the variation on how each visual cue is presented could affect its reliability to deliver desired results. Imagine a person riding an MRT line (Figure 3.C) where visual cues are designed to force riders not to sit on areas covered with plastic materials - a traditional command approach. If the same person were to transfer to another line, let's say LRT Line 2 (Figure 3.B), the person's exposure to a previous train line with a stricter physical distancing protocol might remove the nudging power of visual cues from the remaining train lines.

To address the problem of inconsistencies on nudging measures, the government can form a nudging unit - a team that will support all implementing agencies to design, test, and evaluate behaviorally informed interventions in the country. The National Economic and Development Authority (NEDA), the Philippines' principal socioeconomic planning body that provides policy recommendations to policymakers in congress and the executive branch, can initiate the creation of a nudging unit. Most advanced economies have already established their respective nudging units that integrates behavioral insights with their policy interventions. This trend began in 2010 when UK established their very own Behavioral Insights Unit, also known as BIT (Halpern, 2015). This was followed by other developed countries such as the US, Australia, Canada, the Netherlands, and Germany. Eventually, some developing countries (e.g., India and Indonesia), and other multilateral institutions (e.g., World Bank) followed suit (Azif, 2020).

\section{NUDGING SHOULD ACT AS A COMPLEMENT, NOT A STAND-ALONE SOLUTION}

While nudging measures are already proven to reinforce some policy interventions, it must be noted that nudging is not a stand-alone policy tool to achieve a certain outcome (Ewert, 2020). Policy implementation is a multidimensional endeavor with synergistic components. It only means that nudging measures should be designed to complement another regulatory policy. Nudges that are not aligned with another policy intervention can actually bring more harm than good. Let's take the current situation of Metro Manila under GCQ as an example. Since public transportation is still operating at limited capacitywhere regular jeepneys are still barred to operate, the riding public has limited options to choose from. It only means that train systems must be prepared to accommodate public riders beyond their carrying capacity - making physical distancing almost impossible to implement even with the use of visual cues. Thus, nudging should not be considered as an independent solution but rather as a part of a bigger policy implementation process (Loer, 2019).

\section{CONCLUSIONS}

The evaluation of nudging measures in Metro Manila's major train systems offered important behavioral insights in understanding why some nudges fail and how we can make them work. Even if the desired goal of a nudging measure is clear, a poorly designed nudge can bring more harm than good. To improve the effectiveness of visual cues that are placed in major train systems in Metro Manila, the management must make them informative, inclusive, and consistent to convey simple yet logical information to the commuting public. Moreover, the government can explore to establish a nudging unit that will support all implementing agencies to design, test, and evaluate behaviorally informed interventions in the country. Lastly, nudging should not be considered as a stand-alone policy tool, but rather as a small part of a bigger policy implementation process. 


\section{ENDNOTES}

1. Screen captured from Baguio Midland Courier Facebook Page and Pasig City website (pasigcity.gov.ph)

2. Photos grabbed from a twitter user Lucas, 2020 (@bashgita) and Facebook page Philippine Entertainment (@PhilippineTVOfficial)

3. Photos from left to right: LRT 1 (grabbed from twitter user Lucas, 2020 | @bashgita), LRT 2 (grabbed from Romero, 2020 | One news article), and MRT (grabbed from Malasig, 2020 | InterAksyon news article)

4. A common rule of thumb for legibility is to increase the letter height by 1 inch for every 10 feet of viewing distance away from the signage (Nelson, 2017).

5. Inspired by the studies of Elliot and Maier (2014) and Yoon and Vargas (2018).

\section{REFERENCES}

Afif, Z. (2020, October 15). "Nudge units" - where they came from and what they can do. World Bank Blogs. Retrieved from https://blogs.worldbank.org/developmenttalk/nudge-units-where-theycame-and-what-they-can-do

Baldwin, R. (2014). From regulation to behaviour change: Giving nudge the third degree. The Modern Law Review, 77(6), 831-857.

Botta, R.A., Dunker, K., Fenson-Hood, K., Maltarich, S., \& McDonald, L. (2008). Using a relevant threat, EPPM and interpersonal communication to change hand-washing behaviours on campus. Journal of Communication in Healthcare, 1(4), 373-381.

Calvelo, G. (2020, May 26). LRT-2 tests physical distancing protocols. $A B S-C B N$ News. Retrieved from https://news.abs-cbn.com/news/multimedia/photo/05/26/20/lrt-2-tests-phsyical-distancingprotocols

Cutting, J.E., \& Vishton, P.M. (1995). Perceiving layout and knowing distances: The integration, relative potency, and contextual use of different information about depth. Perception of space and motion (pp. 69-117). Elsevier.

Elliot, A.J., \& Maier, M.A. (2014). Color psychology: Effects of perceiving color on psychological functioning in humans. Annual Review of Psychology, 65, 95-120.

Ewert, B. (2020). Moving beyond the obsession with nudging individual behaviour: Towards a broader understanding of Behavioural Public Policy. Public Policy and Administration, 35(3), 337-360.

Halpern, D. (2015). Inside the nudge unit: How small changes can make a big difference. Random House.

Ibañez, J.P., Espedido, G.L., \& Ang, A.J. (2020, May 29). PHL to open up economy as lockdown eases. BusinessWorld Online. Retrieved from https://www.bworldonline.com/phl-to-open-up-economyas-lockdown-eases/

Judah, G., Aunger, R., Schmidt, W-P., Michie, S., Granger, S., \& Curtis, V. (2009). Experimental pretesting of hand-washing interventions in a natural setting. American Journal of Public Health, 99(S2), S405-S411.

Kahneman, D. (2011). Thinking, fast and slow. Macmillan.

Kabagani, L.J. (2020, May 20). Biz establishments in Pasig told to file 'notice' to resume ops. Philippine News Agency. Retrived from https://www.pna.gov.ph/articles/1103365

Loer, K. (2019). The enzymatic effect of behavioural sciences: What about policy-makers' expectations? Handbook of Behavioural Change and Public Policy. Edward Elgar Publishing.

Lucas. (2020, June 2). The "wala kayong disiplina" crowd is blaming these people for not following instructions, BUT the real problem is bad design. Sino ba kasing nag-isip na X ang sign for "pwedeng umupo/tumayo dito"? [Tweet]. Retrieved from https://twitter.com/bashgita/status/1267750120935718914

Madarang, C.S. (2020, April 28). This is how Baguio City police implements 'social distancing' in public market. Interaksyon. Retrieved from https:/www.interaksyon.com/trendsspotlights/2020/04/28/167347/this-is-how-baguio-city-police-implements-social-distancing-inpublic-market/ 
Malasig, J. (2020, June 3). Some commuters think LRT-1's visual cues are not effective. Here's why. InterAksyon. Retrieved from https://www.interaksyon.com/trendsspotlights/2020/06/03/169896/some-commuters-think-lrt-1s-visual-cues-are-not-effective-hereswhy/

Nelson, J. (2017, July 7). Signage 101 - Letter Height Visibility. Sign.com. Retrieved from https://www.signs.com/blog/signage-101-letter-height-visibility/

Pasig City Government. (2020, May 2). Nagbabago talaga ang behavior natin kapag may "Visual Cues". Retrived from https://www.pasigcity.gov.ph/article-post?news=4592001

Philippine Entertainment. (2020, June 1). Hindi talaga marunong sumunod yung mga bilog [Post]. Retrieved from https://www.facebook.com/PhilippineTVOfficial/posts/10158667534293570

Romero, A. (2020, May 4). Visual Cues, Seating Arrangements In Mass Transport, Warmer Malls, Flexible Learning Under New Normal. One News. Retrieved from https://www.onenews.ph/visual-cues-seating-arrangements-in-mass-transport-warmer-mallsflexible-learning-under-new-normal

Thaler, R.H., \& Sunstein, C.R. (2003). Libertarian paternalism. American Economic Review, 93(2), 175179.

Thaler, R.H., \& Sunstein, C.R. (2009). Nudge: Improving decisions about health, wealth, and happiness. Penguin.

United Nations Development Program. (2020, May 7). Using behavioural insights to respond to COVID19. Retrieved from https://www.undp.org/content/undp/en/home/stories/using-behaviouralinsights-to-respond-to-covid-19-.html

Yoon, G., \& Vargas, P. (2018). The Subtle Influence of Check and X Marks: How Symbolic Markings Influence Judgment. Journal of Consumer Psychology, 28(4), 682-688. 